\title{
ENTRE A SANTIDADE E A LOUCURA: O DESDOBRAMENTO DA MULHER NA BAGAGEM POÉTICA DE ADÉLIA PRADO
}

RESUMO:

Este estudo busca analisar a representação feminina na poesia de Adélia Prado, poeta mineira residente em Divinópolis. Detemo-nos, especificamente, em Bagagem, livro de estréia da autora, publicado em 1976. Utilizamos, como referencial teórico, as discussões de gênero.

PALAVRAS-CHAVE: Adélia Prado, gênero, poesia, representação feminina.

Este estudo busca analisar a representação feminina na poesia de Adélia Prado, poeta mineira residente em Divinópolis. Detemo-nos, especificamente, em Bagagem, livro de estréia da autora, publicado em 1976.

Quando da publicação de seu primeiro livro, a autora chamou a atenção da crítica por construir uma poesia inovadora no cenário da Literatura Brasileira. Inovadora, porque seus versos, longe de reproduzirem as dicotomias verificadas nos textos poéticos até então produzidos por mulheres, buscam uma coexistência dos papéis das mulheres tradicionalmente considerados como excludentes. Se a tradição patriarcal representou a mulher ora como o ser perfeito, dotado de qualidades que nada mais são que idealizações, ora como o ser demoníaco, a Eva do Éden capaz de ludibriar o homem e levá-lo para o abismo, a poesia de Adélia Prado vai além dessas divisões, advogando a representação de um feminino mais complexo e, cremos, mas condizente com a realidade de todo e qualquer sujeito mulher inserido no meio social. Não obstante essa seja a marca do feminino na obra de Prado, marca tão pouco compreendida nos estudos até agora feitos sobre o mesmo, a poeta hoje encontra uma certa resistência por boa parte da Academia e, conseqüentemente, faltam estudos de fôlego sobre sua poesia, principalmente em Minas Gerais.

|* Mestre em Letras: Estudos Literários (Área de concentração: Literatura Brasileira), 2001. 


\section{EMTESE}

Belo Horizonte, v. 6, p. I-253, ago. 2003

Utilizando como referencial teórico as discussões de gênero, conceituamos o feminino e o masculino como construções culturais, e não como dados naturais. Em outras palavras, indo para além das concepções imanentistas de sujeito, as quais pressupõem a existência, por exemplo, de uma essência feminina, de uma psique diferenciada da do homem, baseamo-nos aqui no fato de que ser homem e ser mulher nada mais são do que construções culturais dentre outras. Por esse viés, concordamos com o fato de que ninguém nasce homem ou mulher, mas se torna, aprende a sê-10 numa sociedade que traz, para cada indivíduo, modelos de masculinidade e feminilidade. Acrescentamos, ainda, que não estamos negando a existência de uma psique feminina, tão apregoada pela Psicanálise. 0 que de fato fazemos é reconhecer que a configuração dessa identidade psíquica, e o substantivo "configuração" já aponta para isso, não é algo desde sempre existindo, mas antes um existir que se constrói no seio de uma dada sociedade

Nessa perspectiva, verificamos um desdobramento do feminino na poesia de Adélia Prado, ou seja, uma representação da mulher ora dentro dos referenciais androcêntricos, o que chamamos de "santidade", ora fora dos mesmos, o que denominamos "1oucura".

Esses dois conceitos, santidade e loucura, não foram escolhidos a esmo, mas antes nos foram sugeridos, ou melhor explicitados, pelo discurso poético da autora de Divinópolis. Num dos poemas de Bagagem, o sujeito feminino, referindo-se a uma serenata (e esse é o título do poema), que acontecerá numa "noite de lua pálida e gerânios" (10 verso), fala de um homem amado, que virá para fazer-1he a romântica seresta. Entretanto, como a palidez da lua já nos aponta desde o início do poema, essa serenata nunca acontece, pois o homem nunca vem e a mulher, o único ser que envelhece dentre as coisas, continua esperando. Se algum canto existe, é o dessa mulher; e esse canto é o poema de imagens belíssimas cantando uma espera. "No dia em que ele vier, / porque é certo que vem" - diz-nos ainda o sujeito feminino - "de que modo vou abrir a janela se não for doida? / Como a fecharei se não for santa?".

Doida, portanto, será essa mulher se, mesmo Bela Adormecida às avessas, envelhecida pela força de Chronos, insistir em apresentar-se para uma serenata, o que, espera-se, deve ser feito por uma linda e sempre jovem mulher. Santa ela se 
apresentará se, mesmo já tendo aberto a janela, fechá-la logo depois, abstendo-se de usufruir daquilo que ela tanto deseja: o homem "com boca e mãos incríveis", cujas mãos tocarão uma flauta no jardim.

Se num primeiro momento verificamos que esse desdobramento em Adélia Prado, esse trânsito entre santidade e loucura, manifesta-se, respectivamente, ora no respeito às normas instituídas para o relacionamento amoroso, ora no desrespeito às mesmas, o que vai se configurar numa leitura mais ampla, num segundo momento, é o mesmo trânsito no que diz respeito a todos os outros aspectos de sua obra.

Para o delineamento desse trânsito entre santidade e loucura, é-nos necessário verificar, então, os diversos aspectos pelos quais, na nossa leitura, dá-se o desdobramento do feminino em Adélia Prado, quais sejam: a retomada da tradição literária masculina, a religiosidade e a representação do relacionamento amoroso.

Os modos pelos quais a autora retoma e dialoga com boa parte da tradição literária masculina vão desde uma continuidade dessa tradição até uma ruptura com a mesma. Os escritores com que entra em diālogo são autores bíblicos, Guimarães Rosa, Murilo Mendes, 01 avo Bilac, Fernando Pessoa, Camões e Carlos Drummond de Andrade. Dentre todos, é com este que Adélia vai instaurar um diálogo mais duradouro e, portanto, persistente. Ao dialogar com Carlos Drummond de Andrade, Prado está, de certa forma, dialogando com uma das grandes vozes masculinas da literatura brasileira. Nesse diálogo, vários temas são tratados, como o papel da mulher na sociedade, o papel do homem, do escritor e da escritora, a questão das fontes e influências, da continuidade de um discurso literário qualquer e da ruptura com o mesmo. Os versos de Adélia, em muitos poemas de Bagagem como "endecha", reproduzem o gauchismo de Drummond - o que pode ser, sem dúvida alguma, uma filiação estética; noutros, a voz lírica da poeta divinopolitana admite um certo desconforto quando ouve citarem Carlos Drummond de Andrade - e aqui se percebe, para retomarmos uma expressão de Harold Bloom, uma angústia da influência. Já numa boa parte do mesmo livro, a voz poética adeliana questiona o gauchismo do poeta de Itabira, afirmandose como um ser feminino não gauche / coxo, mas desdobrável - é o que se verifica no primeiro poema, "Com licença poética". 


\section{EMTESE}

Belo Horizonte, v. 6, p. I-253, ago. 2003

A religiosidade, na obra da escritora mineira, também tem duas faces. Ao mesmo tempo em que erige um Deus coercitivo, irado e vingador, o sujeito poético feminino pinta um quadro místico da figura divina, assumindo com ela uma proximidade que subverte os preceitos religiosos ortodoxos. Tal subversão se consubstancia no modo como Prado representa Cristo, na medida em que ela vai buscar no Filho de Deus o que não é apenas divino, mas também corporal e humano. Desse modo, tal religiosidade apregoa ora um Deus que, de acordo com os ensinamentos judaico-cristãos, limita o ser humano na sua precariedade e finitude, ora um Deus de amor e de erotismo, pois corpo e alma não se opõem: sagrado é o corpo e erótica é a alma.

0 relacionamento amoroso puramente humano, nos versos de Adélia Prado, refaz-se dentro dos parâmetros em que o 0cidente o confinou. Surgem, então, nos seus poemas, os temas que toda uma vasta tradição já desenvolveu, como a espera pelo amado, o amor que a tudo alimenta e que a tudo apetece, a submissão feminina no relacionamento amoroso e o erotismo.

Como se poderia pensar de imediato, o erotismo caracterizaria a subversão perpetrada pela mulher adeliana aos parâmetros patriarcais. No entanto, constatamos que o diferencial de Prado não reside aí, visto já termos, na nossa tradição, mulheres escritoras que pelo erótico subvertiam. A poeta mineira diferencia-se por subverter e submeter-se, ao mesmo tempo.

Verificamos, por fim, que a representação do feminino em Adélia Prado vai mais além de um simples dualismo: a mulher aí erigida, ao promover um trânsito entre a "santidade" e a "loucura", assume todos os papéis, sem negar nenhum. Na sua poesia, percebemos uma mulher que, ora assumindo-se escritora, ora não, aproximase e às vezes distancia-se da tradição masculina, quer literária, quer religiosa; mulher que em certos momentos é o "anjo do lar", a figura pacata e resignada que, no relacionamento amoroso, é a própria espera chamando pelo amor ou o silêncio frente ao seu destino, cujo controle não pertence a si, mas ao homem ou a Deus; em outros momentos o que surge é uma mulher irônica, entregue a toda atividade sensorial, indo à busca de algo e negando, portanto, aquela postura de espera. Em todo esse trânsito, o discurso poético é perpassado por posturas otimistas e pessimistas, às vezes alternada e outras simultaneamente. 
Reconhecer-se nessa multiplicidade é "malograr o sonho masculino", na medida em que se refuta uma "representação fragmentada da mulher", nos termos de Lucía Guerra. ${ }^{1}$ E ao construir-se desdobrável na escritura, a mulher faz desta 0 espaço potencialmente privilegiado para vivenciar a si mesma em todas as suas experiências de vida.

NOTAS:

1. Lucia Guerra, em La mujer fragmentada: Historias de um signo, mostra, através de uma análise histórica, como o signo "mulher" foi sendo representado de forma fragmentada pelo homem ao longo dos tempos, ou seja, representado ora como "anjo" ora como "ser demoníaco".

ABSTRACT :

This study, grounded theoretically in discussions about gender, aims at analysing the female representation in the poetry of Adélia Prado, a Brazilian poet who lives in Divinópolis, Minas Gerais. The particular interest of this work relies on her first book, Bagagem, published in 1976.

KEY WORDS: Adélia Prado, gender, poetry, representation of women.

REFERÊNCIAS BIBLIOGRÁFICAS

BEAUVOIR, Simone de. 0 segundo sexo. 3. ed., v. 1 e 2. Trad. Sérgio Milliet. Rio de Janeiro: Nova Fronteira, 1980.

BÍBLIA SAGRADA. N. T. São Mateus. 33. ed. Rio de Janeiro: Imprensa Bíblica Brasileira, 1991. cap. 16:18, p. 22. BL00M, Harold. A angústia da influência: uma teoria da poesia. Rio de Janeiro: Imago, 1991.

CRUZ, Ester Mian da. "Signos da feminilidade em Adélia Prado: traços de uma tradição ibérica". Universitária - Revista das Faculdades Integradas Toledo. Araçatuba: Associação de Ensino Marechal Cândido Rondon. v. 1, n. 1, outubro 1997.

ELIADE, Mircea. O sagrado e profano: a essência das religiões. 4. ed. São Paulo: Martins Fontes, 1999.

GUERRA, Lucia. La mujer fragmentada. Santiago: Cuarto Propio, 1995. 


\section{EM TESE}

Belo Horizonte, v. 6, p. I-253, ago. 2003

HOLLANDA, Heloisa Buarque de (0rg.). Tendências $e$ impasses: o feminismo como crítica da cultura. Rio de Janeiro: Rocco, 1994.

MAÇANEIRO, Marcial. Eros e espiritualidade: desejo e mistério no cotidiano da fé. São Paulo: Paulus, 1997.

MORET, Ana Lúcia. Tradição e modernidade na obra de Adélia Prado. Campinas: UNICAMP, 1993. (Dissertação de Mestrado em Teoria Literária).

PAZ, 0ctavio. A dupla chama - amor e erotismo. São Paulo: Siciliano, 1994.

PEREIRA, Ana Santana Souza de Fontes. De anjo gauche a anjo na contramão - por uma poética do falanjo. Natal: Universidade Federal do Rio Grande Norte, 1998 (Dissertação, Mestrado em Teoria Literária).

PRAd0, Adélia. "Aí nasceu em mim um par de asas" (Entrevista). Suplemento literário de Minas Gerais, Belo Horizonte, ano XIX, n. 925, p. 3-5, junho 1984.

$\overline{1996 .}$ - Poesia reunida. 6. ed. São Paulo: Siciliano,

- "A mulher bacana?" (Entrevista). Ícaro Brasil, p. 38-42, Julho 1999a.

- "Arte como experiência religiosa". Diante do mistério - Psicologia e senso religioso. MASSIMI, Marina; MAHFOUD, Miguel (Org.). São Paulo: Edições Loyola, 1999b.

- "Entrevista". Cadernos de Literatura Brasileira. São Paulo: Instituto Moreira Salles, n. 9, p. 21-39, junho 2000.

QUEIROZ, Vera. Crítica literária e estratégias de gênero. Niterói, Eduff, 1997. p. 103-156.

- O vazio e pleno: a poesia de Adélia Prado. Goiânia: Editora da UFG, 1994.

REIS, Lívia de Freitas; VANNA, Helena; PORTO, Maria Bernadette (Org.). Mulher e Literatura. Niterói/Rio de Janeiro: Eduff, 1999.

RICHMOND, Carolyn. "Adélia Prado: uma voz lírica brasileira (I)". Suplemento literário de Minas Gerais, Belo Horizonte, ano XV, n. 811, p. 8-9, 17 abril 1982.

SÁ, Jorge de. "Presença de Carlos Drummond de Andrade na poesia de Adélia Prado". Ensaios de semiótica, Belo Horizonte: Faculdade de Letras - Departamento de Lingüistica e Teoria da Literatura, ano IV, n. 8, p. 99-106, dezembro 1982.

SOARES, Cláudia Campos. O afã e a insolvência: a marca do dilaceramento na poesia de Adélia Prado. Florianópolis: Universidade Federal de Santa Catarina, 1992. (Dissertação de Mestrado em Literatura Brasileira e Teoria Literária). 